\title{
The impact of postoperative intensive care on outcomes in elective neurosurgical patients in good physical condition: a single centre propensity case-matched study
}

\section{L'influence des soins intensifs postopératoires sur le devenir des patients en bonne santé ayant subi une neurochirurgie non urgente: une étude unicentrique par appariement des scores de propension}

\author{
Yuki Terada, MD · Satoki Inoue, MD • Yu Tanaka, MD • \\ Masahiko Kawaguchi, MD • Katsuji Hirai, MD • \\ Hitoshi Furuya, MD \\ Received: 31 May 2010/Accepted: 16 September 2010/Published online: 2 October 2010 \\ (C) Canadian Anesthesiologists' Society 2010
}

\begin{abstract}
Purpose In the last three years, all elective neurosurgical cases were performed by a single surgeon at Nara Medical University. For the last year and a half, all patients were transferred to a newly created neurosurgical intensive care unit. The purpose of this study was to evaluate the impact of admission to an intensive care unit after elective neurosurgery.

Methods This study was conducted as a retrospective clinical chart review. Institutional ethics approval was waived, and we reviewed the charts of 296 neurosurgical patients who were American Society of Anesthesiologists' physical status I-II. To avoid channelling bias, propensity score analysis was used to generate a set of matched cases (patients transferred to the intensive care unit [ICU]) and controls (patients transferred to the neurosurgical ward). This process resulted in 104 matched pairs of elective surgical patients who did or did not have an ICU admission after surgery. Glasgow outcome scale (GOS) at discharge
\end{abstract}

Y. Terada, MD $\cdot$ S. Inoue, MD $(\varangle) \cdot$ Y. Tanaka, MD .

M. Kawaguchi, MD · H. Furuya, MD

Department of Anesthesiology, Nara Medical University,

840 Shijo-cho, Kashihara, Nara 634-8522, Japan

e-mail: seninoue@naramed-u.ac.jp

S. Inoue, MD · K. Hirai, MD

Division of Intensive Care, Nara Medical University, 840 Shijo-cho, Kashihara, Nara 634-8522, Japan or at three months after the operation was compared as the primary outcome measure. As secondary outcome measures, we also compared rates of severe early complications and patient satisfaction regarding perioperative patient care.

Results With an unmatched population, poor GOS tended to occur more often in the non-ICU group than in the ICU group ( $6.5 \%$ vs $2.3 \%$, respectively). Mortality rates and severe early complication rates also tended to be higher in the non-ICU group than in the ICU group $12.4 \%$ and $5.3 \%$, respectively, non-ICU group vs $0.8 \%$ and $2.3 \%$, respectively, ICU group). However, after propensity score matching, there was no difference regarding the GOS between groups. Both groups showed very high good outcome percentages (98.1\% ICU vs $97.1 \%$ non-ICU). With regard to mortality rates and severe early complications, both groups showed low mortality (0.96\% vs 0.96\%) and complication rates $(2.89 \%$ ICU vs $3.85 \%$ non-ICU). Patient care in the ICU failed to increase patient satisfaction regarding the overall hospital care.

Conclusion The results of this analysis suggest that admission to an ICU after elective neurosurgery has little impact on outcomes.

\section{Résumé}

Objectif Au cours des trois dernières années, toutes les neurochirurgies non urgentes ont été effectuées par un seul chirurgien à la Nara Medical University et, au cours des 18 derniers mois, tous les patients ont été transférés dans une nouvelle unité de soins intensifs en neurochirurgie. L'objectif 
de cette étude était d'évaluer l'influence de l'admission aux soins intensifs après une neurochirurgie non urgente.

Méthode Il s'agissait d'une étude rétrospective fondée sur l'examen des dossiers médicaux. L'approbation éthique n'a pas été nécessaire et on a examiné les dossiers de 296 patients traités en neurochirurgie dont l'état physique était classé I ou II selon l'American Society of Anesthesiologists. Pour éviter tout biais systématique, on a utilisé l'analyse des scores de propension afin d'obtenir un ensemble de cas appariés (patients transférés à l'unité des soins intensifs) et de cas témoins (patients transférés à l'unité de neurochirurgie). Ce processus a permis d'obtenir 104 paires de patients ayant subi une chirurgie non urgente dont l'un avait été admis à l'unité des soins intensifs, et l'autre, à l'unité de neurochirurgie. Le critère de jugement principal était la comparaison des scores de Glasgow au moment du congé ou trois mois après l'intervention. De plus, les taux de complications graves et de satisfaction des patients par rapport aux soins péri-opératoires ont été comparés à titre de critères secondaires.

Résultats Avec une population non appariée, on a observé que les scores de Glasgow faibles étaient plus fréquents dans le groupe non admis aux soins intensifs (2,3\% contre 6,5\%). Les taux de mortalité et d'apparition précoce de complications graves avaient également tendance à être plus élevés dans le groupe non admis aux soins intensifs $(0,8 \%$ contre $2,4 \%$ et $2,3 \%$ contre $5,3 \%$, respectivement). Cependant, on n'a noté aucune différence entre les deux groupes sur l'échelle de Glasgow après l'appariement des scores de propension. Ils présentaient tout deux des pourcentages très élevés d'évolution favorable $(98,1 \%$ admis aux soins intensifs contre 97,1 \% non admis aux soins intensifs). Les taux de mortalité et d'apparition précoce de complications graves des deux groupes étaient peu élevés (0,96\% contre 0,96\% et $2,89 \%$ contre $3,85 \%$, respectivement). Les patients admis à l'unité des soins intensifs ne se sont pas montrés plus satisfaits de l'ensemble des soins reçus lors de leur séjour.

Conclusion Les résultats de cette analyse laissent entendre que l'admission à l'unité des soins intensifs après une neurochirurgie non urgente n'a que très peu d'influence sur le devenir des patients.

Intensive care units (ICUs) staffed with critical care physicians are known to improve patient outcomes. An intensivist's full-time employment has been associated with improved outcomes in pediatric patients ${ }^{1}$ and reduced mortality rates in adult patients following abdominal aortic aneurysm repair. ${ }^{2,3}$ In addition, it has been reported that utilization of a neurointensive care unit team decreased mortality rates, shortened hospital length of stay, and improved patient outcomes in the neurological and neurosurgical populations. ${ }^{4,5}$ Collectively, it is conceivable that intensive care has a significant impact on critically ill patient outcomes. However, it has not been determined whether intensive care based on continuous monitoring (electrocardiogram (ECG), blood pressure, and pulse oximetry $\left[\mathrm{SpO}_{2}\right]$ ) and frequent neurologic evaluation by ICU staff has a significant impact on elective neurosurgical patient outcome in those who are in good physical condition.

We conducted this study as a clinical chart review and evaluated the impact of intensive care on the outcomes in elective neurosurgical patients who were in good physical condition. To reduce the effect of selection bias, we compared patient outcomes in propensity-matched pairs with or without intensive care. ${ }^{6-8}$ Using this technique, we analyzed patients who were equally likely to be treated postoperatively in the ICU or in the neurosurgical ward, and we excluded patients from the analysis if there was a high likelihood of exposure to only one of the postoperative care situations.

\section{Methods}

Since there were no ethical issues associated with this study, it was exempt from institutional review board approval and the requirement for informed consent. This study was performed as a case-control study in accordance with the recommendations of the STrengthening the Reporting of OBservational studies in Epidemiology (STROBE) consensus statement. ${ }^{9}$ We reviewed the last three years of elective neurosurgical cases performed by a single surgeon at Nara Medical University and extracted the records of 296 consecutive neurosurgical patients who were American Society of Anesthesiologists' (ASA) physical status I-II.

\section{Perioperative patient treatment}

During the first year and a half, postoperative patients were transferred to the neurosurgical ward (non-ICU group). During the remainder of the three years, patients were transferred to the ICU (ICU group) after a neurosurgical ICU was established at Nara Medical University. Patients were treated according to the standard institutional neurosurgical protocol, as described below.

The patients had no premedication for anesthesia. Based on institutional protocol, patients who required hypotensive drugs (except for angiotensin receptor blockers) were treated with these medications preoperatively. ${ }^{10}$ After recording blood pressure, heart rate, and oxygen saturation, anesthesia was induced with an intravenous injection of 
propofol $2 \mathrm{mg} \cdot \mathrm{kg}^{-1}$, fentanyl $2 \mu \mathrm{g} \cdot \mathrm{kg}^{-1}$, and vecuronium $0.15 \mathrm{mg} \cdot \mathrm{kg}^{-1}$. Anesthesia was maintained with $1.5-2 \%$ sevoflurane in $40 \%$ oxygen and fentanyl. A bolus of fentanyl $2 \mu \mathrm{g} \cdot \mathrm{kg}^{-1}$ was administered before pinning the stereotactic frame, and additional fentanyl $1 \mu \mathrm{g} \cdot \mathrm{kg}^{-1}$ was injected in five-minute intervals when the systolic blood pressure was elevated to $>140 \mathrm{mmHg}$. Nicardipine was used to control narcotic resistant hypertension.

Routine monitoring of all patients included ECG, noninvasive arterial blood pressure, intra-arterial catheter for arterial blood pressure, $\mathrm{SpO}_{2}$, end-tidal carbon dioxide and sevoflurane concentrations, and rectal temperature.

After completion of the surgical procedures, sevoflurane was discontinued and tracheal extubation was performed in the operating room. Subsequently, the patients in the non-ICU group were transferred to the neurosurgical ward after the intra-arterial catheter was withdrawn. For those patients admitted to the postoperative ward, oxygen administration and ECG monitoring was continued until the next morning. Neurological evaluation, non-invasive blood pressure monitoring, and $\mathrm{SpO}_{2}$ were performed by the nursing staff every three to four hours during the first $12 \mathrm{hr}$ postoperatively. Neurosurgical residents were also available. The ICU group received continuous oxygen administration, ECG, and invasive arterial blood pressure and $\mathrm{SpO}_{2}$ monitoring until the next morning. A neurological evaluation was also performed every two hours during the first $12 \mathrm{hr}$ postoperatively. A certified intensivist was readily available and supervised the ICU team, which included intensive care nurses and a neurosurgical or anesthesia resident. On the following day, patients without complications were transferred to the neurosurgical ward. Until the 14th postoperative day, either the patients themselves or their close relatives completed a questionnaire regarding perioperative patient care by using a simplified patient satisfaction scale (satisfactory, even, dissatisfactory).

The primary outcome measure was the dichotomized Glasgow outcome scale (GOS) $($ good outcome $=$ good recovery/moderate disability; poor outcome $=$ severe disability/vegetative/dead) at discharge or three months after the operation. The secondary outcome measures included the incidence of severe complications, including surgical re-exploration, acute respiratory failure, and cardiac events. Finally, patient satisfaction was also compared between groups. The hospital length of stay was not investigated because no institutional effort to reduce the hospital length of stay had been established during the study period.

\section{Statistical analysis}

A sample size of 104 subjects in each group (yielding a total number of 208 subjects) provided $95 \%$ power to detect an effect size difference of 0.25 between the two groups, with an alpha of 0.05. Initially, 296 ASA physical status I-II neurosurgical patients were enrolled. To begin with, patient outcomes were compared using the initial 296 patients. Next, to avoid channelling bias, we used propensity score analysis to generate a set of matched cases (patients who were transferred to the ICU) and controls (patients who were transferred to the neurosurgical ward). Ultimately, 88 patients were excluded. The propensity score was calculated for each patient based on a logistic regression analysis of the probability of ICU admission using the clinical characteristics. Initially, we compared the clinical characteristics of the ICU and non-ICU groups using the Chi square test or Fisher's exact test for dichotomous variables and the unpaired Student's $t$ test for continuous variables. We considered the following clinical characteristics to be associated with ICU admission: diagnosis (vascular disease or tumour), age, sex, body mass index, neurological status (Glasgow coma scale [GCS]), background illness (hypertension, diabetes mellitus, coronary artery disease, history of heart failure, lung disease), intraoperative variables (anesthesia time, operation time, fluid balance), and adverse intraoperative events (cardiac events, hypotension, arrhythmia, hypoxia, etc.). As suggested by recent statistical research on propensity score development, we used a structured iterative approach to refine this model, with the goal of achieving covariate balance within the matched pairs. ${ }^{11}$ Covariate balance was measured using the standardized difference, where an absolute difference $>10 \%$ was suggested to represent a meaningful covariate imbalance. ${ }^{10}$ We matched ICU patients to non-ICU patients using a greedy-matching algorithm with a calliper width of 0.2 standard deviations (SDs) of the log odds of the estimated propensity score. This method involved sampling without replacement and has been shown to remove $98 \%$ of the bias from measured covariates. ${ }^{12}$ Finally, this procedure yielded 104 ICU patients who were propensity matched to 104 nonICU patients, which was considered an acceptable sample size estimation. The primary and secondary outcome measures were compared by dividing the number of events by the number of cases followed up for the two groups. The McNemar test or the Wilcoxon signed-rank test were used for these matched pair comparisons. ${ }^{11}$ Analyses were completed using Stata/MP version 10.1 (StataCorp LP, Texas, USA) and R 2.11.1. ${ }^{13}$

\section{Results}

The clinical characteristics of the two groups based on 296 consecutive patients are presented in Table 1. The preoperative evaluation of ASA physical status and GCS were similar, and many of the variables were similar (defined by a standardized difference $<10 \%$ ) before matching. The primary and secondary outcomes are summarized in 
Table 1 Clinical characteristics of the two unmatched study groups $(n=296)$
Data are expressed as mean \pm standard deviation or the number of patients. Intraoperative adverse events included transient supraventricular or ventricular arrhythmia, ST depression, hypotension, and accidental one lung ventilation. These events either disappeared spontaneously or were easily treated. ASA = American Society of Anesthesiologists; $\mathrm{ICU}=$ intensive care unit

\begin{tabular}{|c|c|c|c|}
\hline & $\begin{array}{l}\text { ICU } \\
(n=130)\end{array}$ & $\begin{array}{l}\text { Non-ICU } \\
(n=166)\end{array}$ & $\begin{array}{l}\text { Standardized } \\
\text { difference }(\%)\end{array}$ \\
\hline Disease ( $n=$ Vascular/Tumour) & $65 / 65$ & $70 / 96$ & 15.7 \\
\hline Age (yr) & $58.1 \pm 11.8$ & $58.8 \pm 15.2$ & 5.1 \\
\hline Sex $(n=$ Male/Female $)$ & $75 / 55$ & $87 / 79$ & 3.2 \\
\hline Height $(\mathrm{cm})$ & $158.4 \pm 11.5$ & $160.1 \pm 9.0$ & 16.5 \\
\hline Weight (kg) & $59.2 \pm 11.5$ & $59.1 \pm 12.3$ & 0.8 \\
\hline Body mass index $\left(\mathrm{kg} \cdot \mathrm{m}^{-2}\right)$ & $23.2 \pm 3.6$ & $22.9 \pm 3.9$ & 8.0 \\
\hline ASA physical status $(n=\mathrm{I} / \mathrm{II})$ & $35 / 95$ & $51 / 115$ & 8.3 \\
\hline Glasgow Coma Scale $=13(n)$ & 1 & 2 & 4.4 \\
\hline Glasgow Coma Scale $=14(n)$ & 4 & 4 & 4.1 \\
\hline Glasgow Coma Scale $=15(n)$ & 125 & 160 & 1.2 \\
\hline Diabetes mellitus $(n)$ & 12 & 17 & 3.4 \\
\hline Hypertension $(n)$ & 57 & 68 & 5.8 \\
\hline Coronary artery disease $(n)$ & 6 & 7 & 1.9 \\
\hline History of heart failure $(n)$ & 4 & 1 & 18.4 \\
\hline Lung disease $(n)$ & 10 & 16 & 6.9 \\
\hline Operation time $(\min )$ & $257.6 \pm 73.5$ & $244.0 \pm 80.7$ & 17.6 \\
\hline Anesthesia time (min) & $351.4 \pm 79.6$ & $344.0 \pm 83.1$ & 9.1 \\
\hline Infusion (mL) & $2,396.9 \pm 709.5$ & $2,442.6 \pm 761.9$ & 6.2 \\
\hline Transfusion (mL) & $100.9 \pm 207.8$ & $126.3 \pm 260.5$ & 10.8 \\
\hline Urine $(\mathrm{mL})$ & $1,189.3 \pm 646.5$ & $1,095.1 \pm 602.5$ & 15.1 \\
\hline Bleeding (mL) & $256.7 \pm 240.6$ & $296.2 \pm 270.4$ & 15.4 \\
\hline Intraoperative adverse events $(n)$ & 10 & 6 & 17.6 \\
\hline
\end{tabular}

Table 2 Patient outcomes prior to propensity matching

\begin{tabular}{llll}
\hline & $\begin{array}{l}\text { ICU } \\
(n=130)\end{array}$ & $\begin{array}{l}\text { Non-ICU } \\
(n=168)\end{array}$ & $P$ value \\
\hline $\begin{array}{c}\text { Dichotomized GOS } \\
(n=\text { Poor/Good })\end{array}$ & $3 / 127$ & $11 / 155$ & 0.10 \\
$\begin{array}{l}\text { GOS }(n=1 / 2 / 3 / 4 / 5) \\
\begin{array}{c}\text { Severe early } \\
\text { complications }(n)\end{array}\end{array}$ & $1 / 0 / 2 / 4 / 123$ & $4 / 0 / 7 / 4 / 151$ & 0.70 \\
$\begin{array}{c}\text { Patient's satisfaction } \\
(n=\text { dissatisfactory/even/ }\end{array}$ & $0 / 53 / 77$ & 9 & 0.23 \\
$\quad$ satisfactory $)$ & & & 0.78 \\
\hline
\end{tabular}

Data are expressed as the number of patients. Complications observed during the perioperative period were re-surgical exploration, acute respiratory failure, intestinal perforation, and acute cardiac failure ( $n=1,1,1,0$, respectively, ICU group $v s 3,5,0,1$, respectively, nonICU group). ICU $=$ intensive care unit; GOS $=$ Glasgow Outcome Scale

Table 2. There was no difference in the dichotomized GOS between the groups, although poor outcomes tended to occur more often in the non-ICU group. Also, mortality rates tended to be higher in the non-ICU group than in the ICU group ( $2.4 \%$ vs $0.8 \%$, respectively). Similarly, there were no differences in severe early complications, although complication rates tended to be higher in the non-ICU group than in the ICU group (5.3\% vs $2.3 \%$, respectively).
Complications observed during the perioperative period included re-surgical exploration, acute respiratory failure, intestinal perforation, and acute cardiac failure $(n=$ $1,1,1,0$, respectively, ICU group vs 3,5,0,1, respectively, non-ICU group). Patient satisfaction in terms of the overall hospital care did not differ between the two groups.

The clinical characteristics of the two matched groups extracted by the propensity analysis are presented in Table 3. The average propensity scores of both groups were $0.531 \mathrm{ICU}$ group and 0.529 non-ICU group, respectively. Covariates were well balanced after matching. Notably, preoperative physical and neurologic evaluations were balanced according to ASA physical status and GCS, and the cores indicated a relatively healthy population. The primary and secondary outcomes after propensity score matching are summarized in Table 4. Both groups showed very high percentages of good outcomes. There was no difference in the dichotomized GOS, mortality $(0.96 \%)$, or severe early complications, (2.89\% ICU group vs 3.85\% non-ICU group). Complications observed during the perioperative period were re-surgical exploration, acute respiratory failure, and intestinal perforation $(n=1,1,1$, respectively, ICU group vs 2,2,0, respectively, non-ICU group). Patient care in the ICU did not increase patient satisfaction regarding the overall hospital care. 
Table 3 Clinical characteristics of the two study groups after propensity score matching
Data are expressed as the mean \pm standard deviation or the number of patients.

Intraoperative adverse events included transient

supraventricular or ventricular arrhythmia, ST depression, and accidental one lung ventilation. These either disappeared spontaneously or were easily treated. ASA = American Society of Anesthesiologists; ICU = intensive care unit; GCS $=$ Glasgow coma scale

\begin{tabular}{llll}
\hline & $\begin{array}{l}\text { ICU } \\
(n=104)\end{array}$ & $\begin{array}{l}\text { Non-ICU } \\
(n=104)\end{array}$ & $\begin{array}{l}\text { Standardized } \\
\text { difference }(\%)\end{array}$ \\
\hline Propensity Score & $0.531 \pm 0.127$ & $0.529 \pm 0.128$ & 1.6 \\
Disease $(n=$ Vascular/Tumour) & $50 / 54$ & $55 / 49$ & 9.6 \\
Age $(\mathrm{yr})$ & $57.1 \pm 12.0$ & $56.8 \pm 14.9$ & 2.2 \\
Sex $(n=$ Male/Female) & $48 / 56$ & $47 / 57$ & 1.9 \\
Height $(\mathrm{cm})$ & $159.7 \pm 8.6$ & $160.4 \pm 9.3$ & 7.8 \\
Weight $(\mathrm{kg})$ & $59.5 \pm 12.1$ & $59.2 \pm 13.1$ & 2.4 \\
Body mass index $\left(\mathrm{kg} \cdot \mathrm{m}^{-2}\right)$ & $23.2 \pm 3.5$ & $22.9 \pm 3.7$ & 8.3 \\
ASA physical status $(n=\mathrm{I} / \mathrm{II})$ & $32 / 72$ & $35 / 69$ & 3.4 \\
GCS $=13(n)$ & 1 & 1 & 0.0 \\
GCS $=14(n)$ & 2 & 1 & 8.0 \\
GCS $=15(n)$ & 101 & 102 & 6.2 \\
Diabetes mellitus $(n)$ & 11 & 10 & 3.1 \\
Hypertension $(n)$ & 45 & 43 & 3.8 \\
Coronary artery disease $(n)$ & 5 & 4 & 4.7 \\
History of heart failure $(n)$ & 2 & 1 & 8.0 \\
Lung disease $(n)$ & 10 & 9 & 3.3 \\
Operation time $($ min $)$ & $249.1 \pm 74.2$ & $245.1 \pm 89.6$ & 4.9 \\
Anesthesia time $(\mathrm{min})$ & $335.2 \pm 74.9$ & $340.6 \pm 89.4$ & 6.5 \\
Infusion $(\mathrm{mL})$ & $2,444.7 \pm 737.3$ & $2,406.9 \pm 836.8$ & 4.8 \\
Transfusion $(\mathrm{mL})$ & $98.5 \pm 210.5$ & $116.7 \pm 225.0$ & 8.4 \\
Urine $(\mathrm{mL})$ & $1,166.3 \pm 627.4$ & $1,126.1 \pm 602.3$ & 6.5 \\
Bleeding $(\mathrm{mL})$ & $253.4 \pm 263.4$ & $230.1 \pm 281.4$ & 8.5 \\
Intraoperative adverse events $(n)$ & 6 & 4 & \\
\hline & & & \\
\hline
\end{tabular}

Table 4 Patient outcomes after propensity score matching

\begin{tabular}{llll}
\hline & $\begin{array}{l}\text { ICU } \\
(n=104)\end{array}$ & $\begin{array}{l}\text { Non-ICU } \\
(n=104)\end{array}$ & $P$ value \\
\hline $\begin{array}{c}\text { Dichotomized GOS } \\
(n=\text { Poor/Good })\end{array}$ & $2 / 102$ & $3 / 101$ & 0.99 \\
$\begin{array}{c}\text { GOS }(n=1 / 2 / 3 / 4 / 5) \\
\begin{array}{c}\text { Severe early } \\
\text { complications }(n)\end{array}\end{array}$ & $1 / 0 / 1 / 3 / 99$ & $1 / 0 / 2 / 2 / 99$ & 0.85 \\
$\begin{array}{c}\text { Patient satisfaction } \\
(n=\text { dissatisfactory/ }\end{array}$ & $0 / 34 / 70$ & 4 & 0.99 \\
even/satisfactory) & & $2 / 48 / 54$ & 0.09 \\
\hline
\end{tabular}

Data are expressed as the number of patients

Complications observed during the perioperative period were re-surgical exploration, acute respiratory failure, and intestinal perforation ( $n=1,1,1$, respectively, ICU group $v s 2,2,0$, respectively, non-ICU group). ICU = intensive care unit; GOS = Glasgow outcome scale

\section{Discussion}

In the present study, we investigated the impact of admitting patients in good physical condition to intensive care after elective neurosurgery. Based on this retrospective analysis of patient data, postoperative admission to an intensive care unit failed to change any meaningful neurological outcomes or the rate of early complications. Most of the patients exhibited a good outcome and no early complications regardless of postoperative intensive care. This study suggests that patients with little preoperative morbidity routinely have very good outcomes and further improvements would be very difficult to demonstrate.

As noted above, ICUs that are staffed with critical care physicians are known to improve patient outcome. Varelas et al. reported that a neurointensivist-led team model showed a $4 \%$ relative reduction of the in-hospital mortality rate and improved documentation of the GCS score (from $60.4 \%$ to $82 \%$ ) in head injury patients. ${ }^{4}$ Mirski et al. also found that introducing a team to ICUs that is specifically trained for neuroscience critical care decreased mortality from $36 \%$ to $19 \%$ and increased the proportion of good outcomes in patients with intracranial hemorrhage from $48 \%$ to $69 \%$. $^{5}$ Compared with these reports, our patients in both groups had much lower mortality rates $(0.96 \%)$ and much improved neurological outcomes (complication rates were $<5 \%$ ). Taking into consideration that baseline outcomes were considerably improved in our patient population, it would be difficult to improve patient outcome without any interventions.

Patients with critical neurologic diseases, such as head injury or intracranial hemorrhage, are more critical 
compared with elective neurosurgical patients. Clearly, these patients require intensive care with experienced staff. For such patients, the neurointensive care unit can counteract the development of secondary brain damage by avoiding secondary insults. ${ }^{14}$ However, it is likely a rarity that elective neurosurgical patients in good physical condition become critical and develop secondary brain damage following a primary surgical insult. Therefore, postoperative intensive care is theoretically unnecessary for such patients, except in the case of a life-threatening adverse event occurring during the perioperative period. Rather, intensive care with continuous monitoring might be considered excessive care resulting in a reduction in patient satisfaction ${ }^{15}$ and the development of ICU-related adverse events. ${ }^{16}$ In particular, continuous monitoring with peripheral arterial catheters can also be associated with complications, although none of the patients in our study developed arterial catheter-related complications. ${ }^{17}$ Therefore, postoperative intensive care for elective neurosurgical patients with good physical status might emphasize the unfavourable effects of the ICU on the overall patient condition rather than promote the beneficial effects of the ICU on patient outcome. Our ICU patients appeared to rate perioperative patient care relatively highly, perhaps because they were under the impression that intensive care is the best care. However, it is difficult to interpret this result because a patient's impression of the medical performance may depend on that particular patient's cultural background.

There is a growing interest in the use of propensity score-based methods in observational studies to estimate treatment effects. The propensity score is defined as the conditional probability of assigning a subject to a particular treatment protocol given a vector of measured covariates. $^{7,18}$ To minimize the effect of selection bias on the outcomes, we used propensity score matching for clinical characteristics and excluded distortion of confounding factors. However, this study was retrospective in nature; thus, it should be considered that unmeasured variables could still confound the results.

In conclusion, intensive care did not exhibit significant differences regarding neurological outcomes and the rates of severe early complications for elective neurosurgical patients in good physical condition. For elective neurosurgical patients in good physical shape, it might be difficult to expect further improvement of patient outcome by providing intensive care based on continuous monitoring and frequent neurologic evaluation. On the contrary, intensive care might have a negative impact on elective neurosurgical patients in terms of patient satisfaction and adverse events.

Conflicts of interest The authors declare that no conflicts of interest were involved in this study. This study was supported by departmental funds only.

\section{References}

1. Pollack MM, Katz RW, Ruttimann UE, Getson PR. Improving the outcome and efficiency of intensive care: the impact of an intensivist. Crit Care Med 1988; 16: 11-7.

2. Pronovost PJ, Jenckes MW, Dorman T, et al. Organizational characteristics of intensive care units related to outcomes of abdominal aortic surgery. JAMA 1999; 281: 1310-7.

3. Young MP, Birkmeyer JD. Potential reduction in mortality rates using an intensivist model to manage intensive care units. Eff Clin Pract 2000; 3: 284-9.

4. Varelas PN, Eastwood D, Yun HJ, et al. Impact of a neurointensivist on outcomes in patients with head trauma treated in a neurosciences intensive care unit. J Neurosurg 2006; 104: 713-9.

5. Mirski MA, Chang CW, Cowan R. Impact of a neuroscience intensive care unit on neurosurgical patient outcomes and cost of care: evidence-based support for an intensivist-directed specialty ICU model of care. J Neurosurg Anesthesiol 2001; 13: 83-92.

6. Joffe MM, Rosenbaum PR. Invited commentary: propensity scores. Am J Epidemiol 1999; 150: 327-33.

7. D'Agostino $R B J r$. Propensity score methods for bias reduction in the comparison of a treatment to a non-randomized control group. Stat Med 1998; 17: 2265-81.

8. Drake C, Fisher L. Prognostic models and the propensity score. Int J Epidemiol 1995; 24: 183-7.

9. Vandenbroucke JP, von Elm E, Altman DG, et al. Strengthening the Reporting of Observational Studies in Epidemiology (STROBE): explanation and elaboration. Ann Intern Med 2007; 147: W163-94.

10. Bertrand M, Godet G, Meersschaert K, Brun L, Salcedo E, Coriat $P$. Should the angiotensin II antagonists be discontinued before surgery? Anesth Analg 2001; 92: 26-30.

11. Austin PC. Propensity-score matching in the cardiovascular surgery literature from 2004 to 2006: a systematic review and suggestions for improvement. J Thorac Cardiovasc Surg 2007; 134: $1128-35$.

12. Rosenbaum $P R$, Rubin $D B$. Constructing a control group using multivariate matched sampling methods that incorporate the propensity score. Am Stat 1985; 39: 33-8.

13. The R Project for Statistical Computing. R Project Website. Available from URL: http://www.R-project.org (accessed May 31, 2010).

14. Enblad P, Persson L. Impact on clinical outcome of secondary brain insults during the neurointensive care of patients with subarachnoid haemorrhage: a pilot study. J Neurol Neurosurg Psychiatry 1997; 62: 512-6.

15. Roberts BL, Rickard CM, Rajbhandari D, Reynolds P. Factual memories of ICU: recall at two years post-discharge and comparison with delirium status during ICU admission-a multicentre cohort study. J Clin Nurs 2007; 16: 1669-77.

16. Forster AJ, Kyeremanteng $K$, Hooper J, Shojania $K G$, van Walraven $C$. The impact of adverse events in the intensive care unit on hospital mortality and length of stay. BMC Health Serv Res 2008; 8: 259.

17. Scheer B, Perel A, Pfeiffer UJ. Clinical review: complications and risk factors of peripheral arterial catheters used for haemodynamic monitoring in anaesthesia and intensive care medicine. Crit Care 2002; 6: 199-204.

18. Rubin $D B$. Estimating causal effects from large data sets using propensity scores. Ann Intern Med 1997; 127: 757-63. 